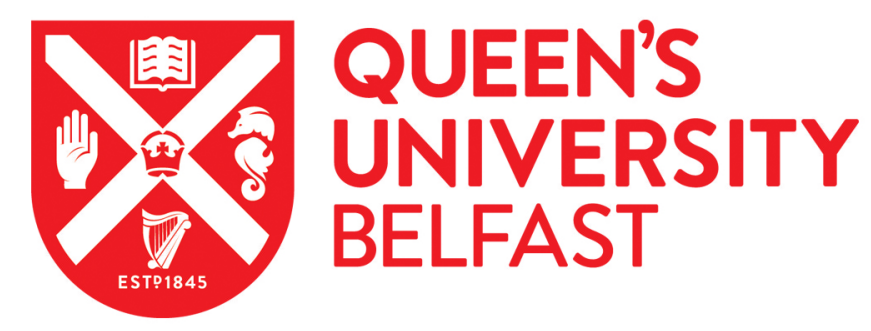

\title{
When are total concentrations not total? Factors affecting geochemical analytical techniques for measuring element concentrations in soil
}

Mcllwaine, R., Cox, S. F., \& Doherty, R. (2015). When are total concentrations not total? Factors affecting geochemical analytical techniques for measuring element concentrations in soil. Environmental Science and Pollution Research, 22(8), 6364-6371. https://doi.org/10.1007/s11356-015-4204-5

\section{Published in:}

Environmental Science and Pollution Research

\section{Document Version:}

Peer reviewed version

Queen's University Belfast - Research Portal:

Link to publication record in Queen's University Belfast Research Portal

\author{
Publisher rights \\ Copyright Springer-Verlag Berlin Heidelberg 2015. \\ The final publication is available at Springer via http://dx.doi.org/10.1007/s11356-015-4204-5.
}

\section{General rights}

Copyright for the publications made accessible via the Queen's University Belfast Research Portal is retained by the author(s) and / or other copyright owners and it is a condition of accessing these publications that users recognise and abide by the legal requirements associated with these rights.

Take down policy

The Research Portal is Queen's institutional repository that provides access to Queen's research output. Every effort has been made to ensure that content in the Research Portal does not infringe any person's rights, or applicable UK laws. If you discover content in the Research Portal that you believe breaches copyright or violates any law, please contact openaccess@qub.ac.uk. 
2 When are total concentrations not total? Factors affecting geochemical analytical

3 techniques for measuring element concentrations in soil

\section{Authors}

5 Rebekka Mcllwaine ${ }^{1 *}$, Siobhan F. Cox ${ }^{1}$ and Rory Doherty ${ }^{1}$

$6 \quad{ }^{1}$ Environmental Engineering Research Centre

7 School of Planning, Architecture and Civil Engineering

8 Queen's University Belfast

9 Belfast BT9 5AG

10 UK

$11{ }^{*}$ Corresponding Author

12 Email: rmcilwaine05@qub.ac.uk

13 Phone: +44 (0)28 90974006

\section{Abstract}

15 Inductively coupled plasma (ICP) following aqua regia digestion and $\mathrm{x}$-ray fluorescence 16 (XRF) are both geochemical techniques used to determine 'total' concentrations of elements 17 in soil. The aim of this study is to compare these techniques, identify elements for which 18 inconsistencies occur and investigate why they arise. A study area $\left(\sim 14000 \mathrm{~km}^{2}\right)$ with a 19 variety of total concentration controls and a large geochemical dataset $(n=7950)$ was 20 selected. Principal component analysis determined underlying variance in a dataset composed of both geogenic and anthropogenic elements. Where inconsistencies between the techniques were identified, further numerical and spatial analysis was completed. The techniques are more consistent for elements of geogenic sources and lead, whereas other elements of anthropogenic sources show less consistency within rural samples. XRF is affected by sample matrix while the form of element affects ICP concentrations. Depending on their use in environmental studies, different outcomes would be expected from the techniques employed, suggesting the choice of analytical technique for geochemical analyses may be more critical than realised.

\section{Keywords}

30 X-ray fluorescence; inductively coupled plasma; aqua regia extraction; geogenic; 31 anthropogenic; soil; total element concentrations 
XRF and ICP with either mass or optical emission spectrometry (ICP-MS or ICP-OES) are two analytical techniques frequently used in geochemical surveys. XRF concentrations are commonly regarded as total (Salminen and Tarvainen 1997; Kisser 2005; Johnson et al 2010), whereas ICP concentrations are heavily dependent on the preceding acid extraction. ICP concentrations measured following an aqua regia digestion are sometimes referred to as total (Niskavaara et al 1997; Sahuquillo et al 2003) and sometimes as extractable or leachable concentrations (Salminen and Tarvainen 1997; Moor et al 2001; Peltola and Aström 2003; Carrero et al 2013).

During XRF analysis a prepared and homogenised soil sample is irradiated with primary $\mathrm{x}$ rays, causing x-rays of characteristic wavelengths to be emitted (Dzubay 1978; Gill 1997) which are then analysed using either an energy dispersive (ED) system (Dzubay 1978) or a wavelength dispersive (WD) system (Fifield and Haines 1995). Prepared soils for ICP analysis undergo an acid digestion procedure e.g. aqua regia (traditionally 3 parts hydrochloric acid to 1 part nitric acid) prior to analysis (Thornton 1983; Gill 1997). Numerous studies compare the variations of acid digestion methods that exist (Bettinelli et al 2000; Sastre et al 2002; Tighe et al 2004). Closed vessel microwave digestions have become more popular in recent years; the EPA Method 3051A (United States EPA 2007) combines a concentrated nitric acid (sometimes with added hydrochloric acid) extraction with a closed vessel microwave digestion. Following the chosen digestion method, the diluted supernatent is injected through a plasma torch, and as the excited atoms return to their lower states either the energy emitted (OES) or a count of individual emitted ions (MS) is measured (Gill 1997).

Previous studies comparing these analytical techniques have employed a small number of samples (Jarva et al 2009), heavily contaminated soil samples (Chander et al 2008) or used the comparison to indicate the mineralogical host of trace elements (Cohen et al 2012). It is important to know whether the analytical techniques employed do give 'total' concentrations within soil samples or if they are affected by the element being measured, the source of the element and therefore its form, and the sample matrix. If we can better understand where consistency between the techniques deteriorates for an element this will inform all users of geochemical data, particularly data for samples analysed by XRF or ICP following aqua regia digestion. Increasing our understanding of the benefits and limitations of each technique will inform the choice of analytical techniques for future surveys. Here we show the differences between two techniques using a large number $(n=7950)$ of soil samples in a region with extremely varied geology and land use. Elements are identified for which there are inconsistencies between the techniques and inconsistencies are mapped spatially.

\section{2. Materials and Method}

\subsection{Study area}

The study area (Northern Ireland, $\sim 14000 \mathrm{~km}^{2}$ ) is recognised as having extremely diverse geology (Mitchell 2004) and a variety of concentration controls that enable determination of inconsistencies between the analytical techniques. Bedrock geology, superficial geology and anthropogenic influences are all factors that are known to control total concentrations of elements (as measured by XRF) in shallow soils (Jordan et al 2007; Johnson and Ander 2008; Candeias et al 2011; Mcllwaine et al 2014). Figure 1c summarises previously 
identified controls on XRF concentrations for arsenic (As), chromium (Cr), copper (Cu), nickel (Ni), lead (Pb) and vanadium (V) within Northern Ireland (Mcllwaine et al 2014). These include areas of extrusive basalt, Devonian sandstone and intrusive granite bedrock, agreeing with previous research by Barrat and Nesbitt (1996), Hill et al (2001) and Green et al (2010). The urban domain is recognised to control the concentrations of some elements (Wong et al 2006; Albanese and Breward 2011), as are areas of peat (Shotyk et al 1996; Nieminen et al 2002) and mineralised areas (Reimann and Garrett 2005).

\subsection{Tellus geochemical dataset}

The Tellus survey, managed by the Geological Survey of Northern Ireland, was completed between 2004 and 2007 (http://www.bgs.ac.uk/gsni/tellus/). As part of this survey, geochemical analyses were completed on 7,950 shallow soil samples, taken between 5 and $20 \mathrm{~cm}$ depth, with each composite sample consisting of five auger flights from a $20 \mathrm{~m}$ by $20 \mathrm{~m}$ grid. Concentration data analysed by both XRF and ICP following aqua regia digestion (open vessel analysis with 2 parts nitric acid to 1 part hydrochloric acid) are available for the entire study area for the elements shown in Online Resource 1. Areas designated as urban witnessed a higher sampling density $\left(4\right.$ samples per $\left.\mathrm{km}^{2}\right)$ than the regional areas ( 1 sample per $2 \mathrm{~km}^{2}$ ). A thorough explanation of the sampling, analysis and quality assurance of the Tellus campaign has been published (Smyth 2007; Green et al 2010).

\subsection{Underlying variance in dataset}

As, cobalt (Co), $\mathrm{Cr}, \mathrm{Cu}$, molybdenum (Mo), $\mathrm{Ni}, \mathrm{Pb}$, antimony ( $\mathrm{Sb}$ ), tin ( $\mathrm{Sn}$ ) and $\mathrm{V}$ were selected for assessment to determine controlling factors over concentrations measured by both techniques as they originate from a variety of sources with differing spatial distributions. XRF and ICP concentrations were included in a principal component analysis (PCA) to determine the underlying variance within the dataset, identify behaviour patterns and create groups of elements for further study. PCA eliminates 'noise' from multivariate data and presents variability in a reduced number of components (Reimann et al 2007; Candeias et al 2011; Yunker et al 2012). Due to the compositional nature of geochemical data, a centred logratio transformation (Reimann et al 2008) was completed on the dataset prior to PCA. The principal component (PC) scores for each sample location were mapped to gain an understanding of spatial controls. Inverse distance weighting (output cell size of $250 \mathrm{~m}$, power of two and fixed search radius of $1500 \mathrm{~m}$ ), was used to create all interpolated maps in this study. Map classifications were produced using the empirical cumulative distribution function (ECDF) mapping method (Mcllwaine et al 2014), which is an informative method of mapping using classes based on the data distribution (Díez et al 2007; Reimann et al 2008).

\subsection{Consistency between techniques}

Based on the initial assessment, elements of interest were plotted (using log transformed concentrations which more closely approximated the normal distribution) to compare XRF and ICP concentrations. Boxplots were used to visualise how the ratio (XRF/ICP concentrations) varies between the elements, by considering both the variance between the whiskers and the number of outliers. Spatial mapping of the ratio produced maps that highlighted the greatest inconsistencies between the techniques. The ECDF method was used to determine boundaries of the classes on the map, with an additional boundary added where the techniques were equal. Statistical analyses were completed using $R$ statistical software (R Core Team 2013) and maps were produced using ArcMap 10.0 (ESRI 2009). 
3. Results and Discussion
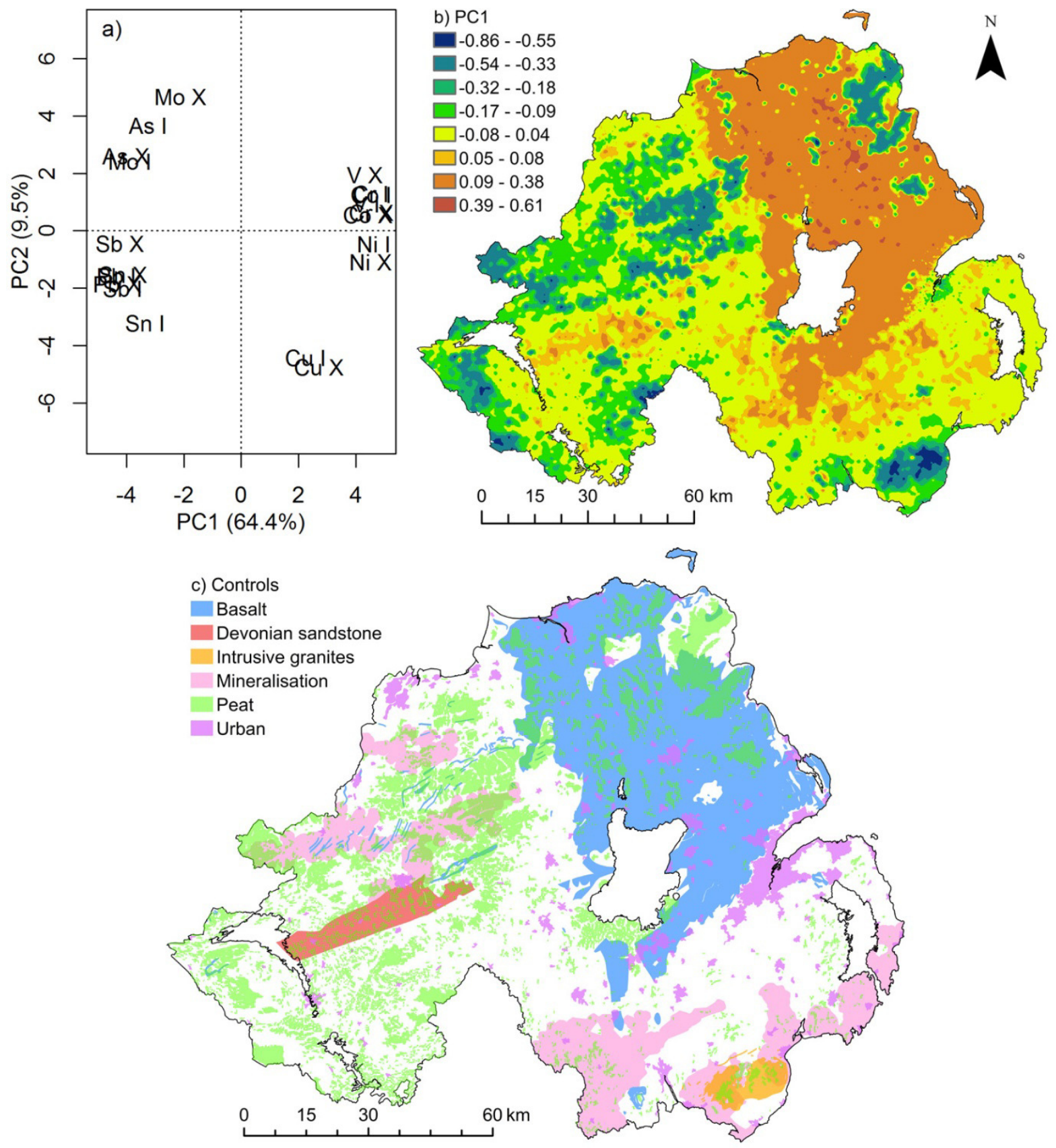

122 Fig 1 Results of PCA completed on the centred logratio transformed XRF and ICP concentrations of As, $\mathrm{Co}, \mathrm{Cr}, \mathrm{Cu}, \mathrm{Mo}, \mathrm{Ni}, \mathrm{Pb}, \mathrm{Sb}, \mathrm{Sn}$ and $\mathrm{V}$ in the shallow soil samples including (a) biplot of PC 1 against PC 2 (X and I denote XRF and ICP respectively), (b) interpolated map of PC1 scores and $c$ ) summary of the main controls found over total element concentrations (by XRF) (Mcllwaine et al 2014) (AFBI data set (Jordan and Higgins 2009) used to identify peat)

PC 1 explains $64.4 \%$ of variance within the dataset. PC1 scores are related to geogenic concentrations of $\mathrm{Ni}, \mathrm{Cr}, \mathrm{Co}, \mathrm{V}$ and $\mathrm{Cu}$ in areas of basalt bedrock geology (Figure 1b). Negative PC scores are related to a diffuse airborne anthropogenic source of $\mathrm{Pb}, \mathrm{Sb}, \mathrm{Sn}, \mathrm{As}$ and Mo in urban areas and topographically elevated blanket peats. PC 2 explains $9.9 \%$ of the variance within the data set and is likely to be related to biogeochemical processes with 
133 elements that display a positive loading such as Mo (Barron et al 2008), V (Bellenger et al 134 2011), As (Stolz and Oremland 1999) and Co (Garnham et al 1993) all taking part in 135 biological or biogeochemical cycling.

136 From this PCA, it is apparent that the two techniques are strongly correlated for elements of 137 geogenic source ( $\mathrm{Co}, \mathrm{Cr}, \mathrm{Cu}, \mathrm{Ni}$ and $\mathrm{V}$ ) as the XRF and ICP loading outputs plot closely on 138 the PCA (Figure 1a). For elements of anthropogenic sources, only Pb shows a strong 139 correlation between the techniques (see also Figure 2c,f) with XRF and ICP loading outputs 140 for Sn, Sb, Mo and As all more widely distributed on the biplot. This shows greater 141 consistency between the techniques for $\mathrm{Pb}$ and the geogenic elements and greater 142 variability between the techniques for $\mathrm{As}, \mathrm{Mo}, \mathrm{Sb}$ and $\mathrm{Sn}$. 
a) As

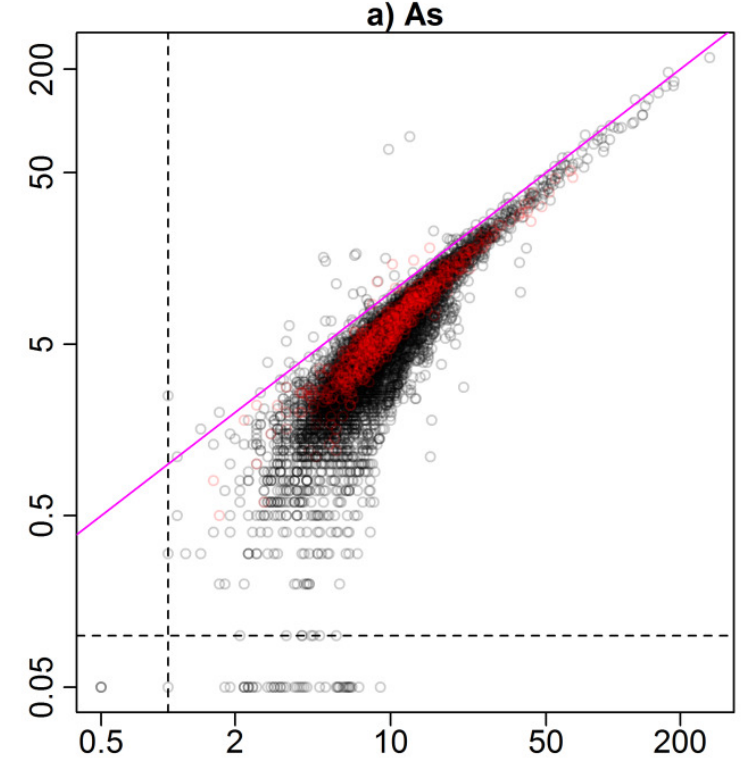

c) $\mathrm{Pb}$

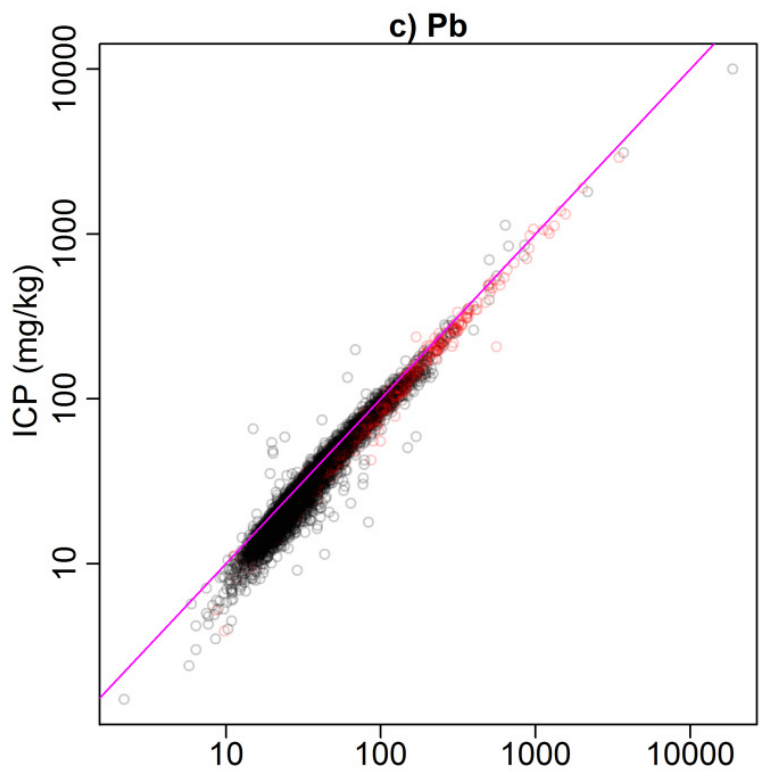

e) $\mathrm{Sn}$

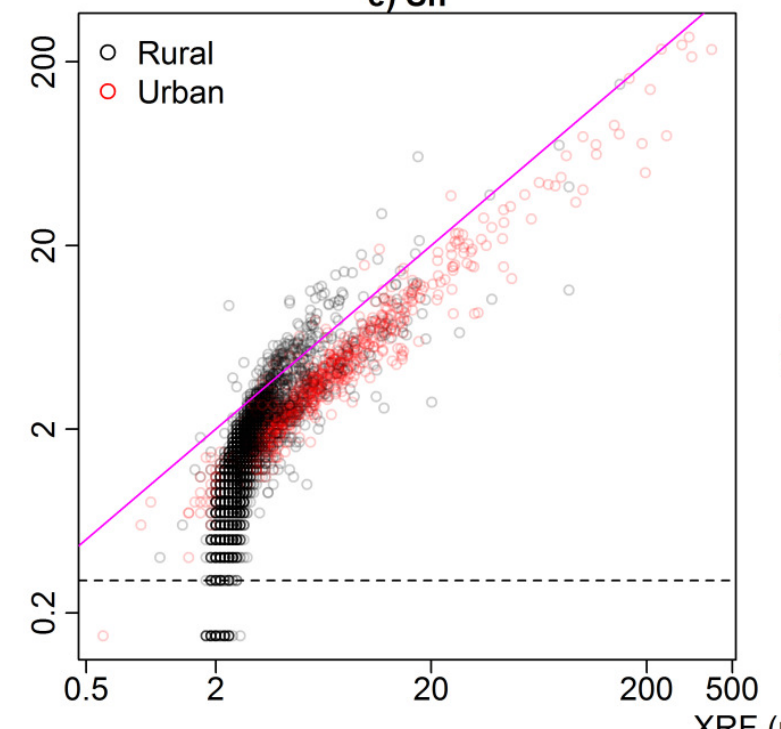

b) Mo

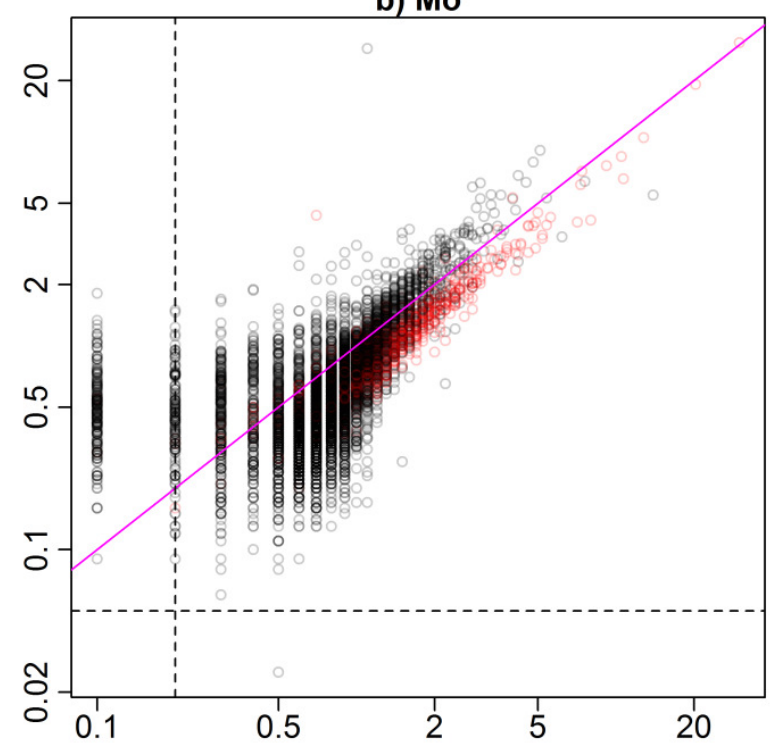

d) $\mathrm{Sb}$

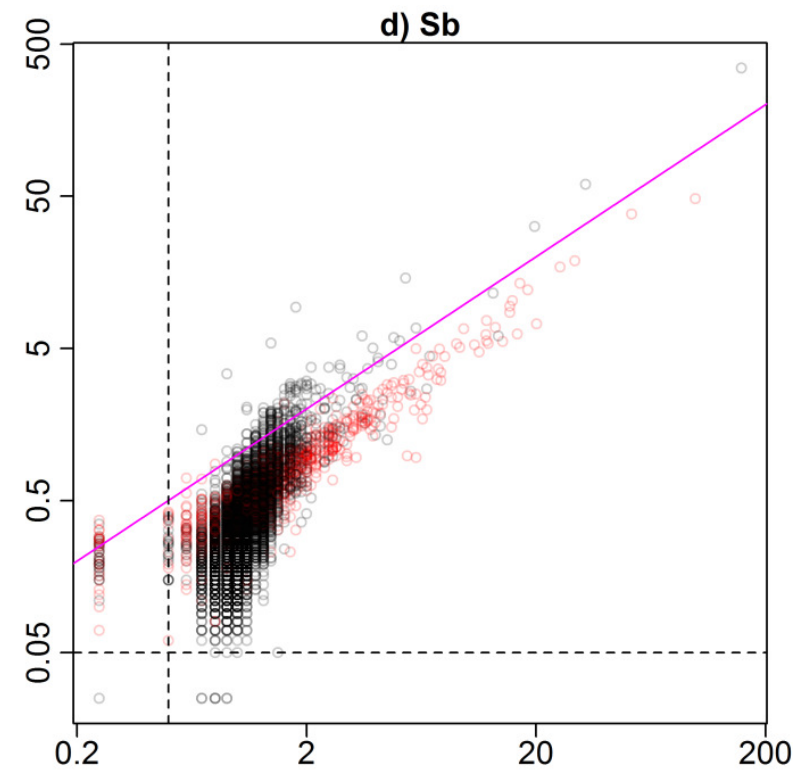

f)

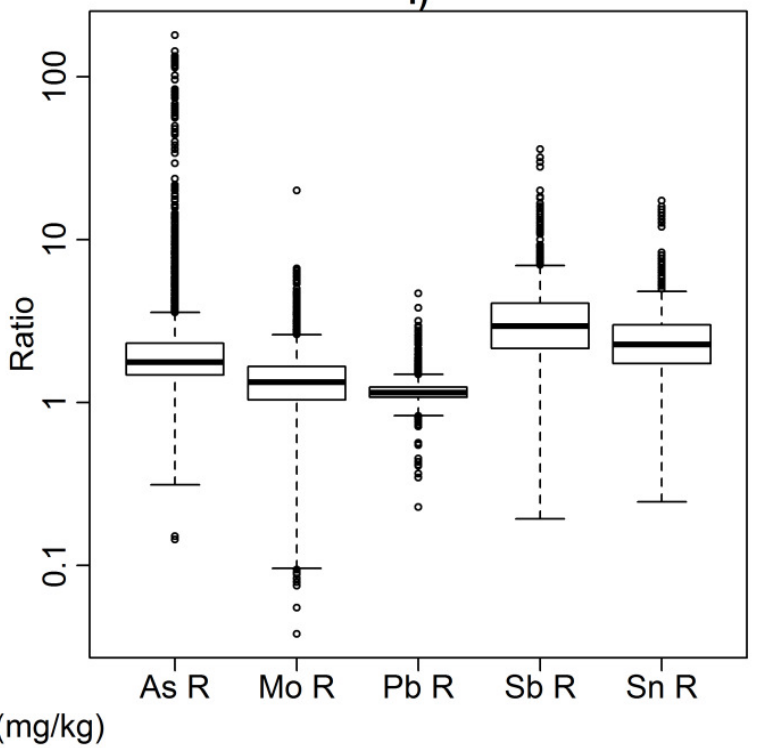


144 Fig 2 Comparison of the analytical techniques using log transformed scatterplots of XRF concentrations against ICP concentrations for a) As, b) Mo, c) Pb, d) Sb and e) Sn (magenta line demonstrates where techniques are equal, rural samples shown in black, urban samples shown in red and dashed lines show method detection limits where appropriate) and f) boxplots for the log transformed ratio (XRF/ICP concentrations) for $\mathrm{As}, \mathrm{Mo}, \mathrm{Pb}, \mathrm{Sb}$ and $\mathrm{Sn}$ in shallow soil samples (whisker locations calculated as box extended by 1.5 times the length of the box in both directions)

151 For As, the analytical techniques become more similar in their measurements as concentrations increase (Figure 2a). The ratio ranges between 0.31 (lower whisker) and 3.57 (upper whisker), with many outliers present above the upper whisker (Figure 2f). At the lowest concentrations of As $(2-10 \mathrm{mg} / \mathrm{kg})$ the difference between the XRF and ICP concentrations are most obvious, with XRF measuring substantially higher concentrations than ICP. In the mineralisation domains for As, ICP concentrations are similar, or even greater than XRF concentrations (Figures 1c, 3a); suggesting As is more easily extracted from these particular areas of elevated concentrations, compared to the remainder of the 159 study area.

160 In the case of Mo, Sb and Sn a split in gradient occurs on the scatterplots (Figures $2 b, d, e$ ) 161 with rural samples (black) showing a steeper gradient than those taken in urban areas (red). The urban samples show a similar trend to $\mathrm{Pb}$ and $\mathrm{As}$, with XRF measuring higher concentrations than ICP. Although Mo, Sb and $\mathrm{Sn}$ are typically anthropogenic in origin and related to combustion sources, Figure 3 shows that inconsistencies between the methods are not related to urban areas but to specific rural areas such as peatlands where anthropogenic contaminants find depositional environments that act as sinks. At elevated rural concentrations ICP measures more than XRF, suggesting Mo, Sb and Sn are more easily extracted from soils in these sampling areas, possibly because they are present in a different form. From Figure $2 f$ the ratios for Mo, $\mathrm{Sb}$ and $\mathrm{Sn}$ all have large ranges $(0.10$ to $2.61,0.19$ to 6.92 and 0.25 to 4.80 respectively) between the lower and upper whiskers as a result of the inconsistency between the techniques for rural samples. For all three elements proximity to the detection limit and reporting of data to one significant figure has created banding at the lowest concentrations shown in the scatterplots (Figures $2 b, d, e$ ). All of these datasets contain less than $1 \%$ of non-detects, except the XRF data for Mo $(2.6 \%$ nondetects). 


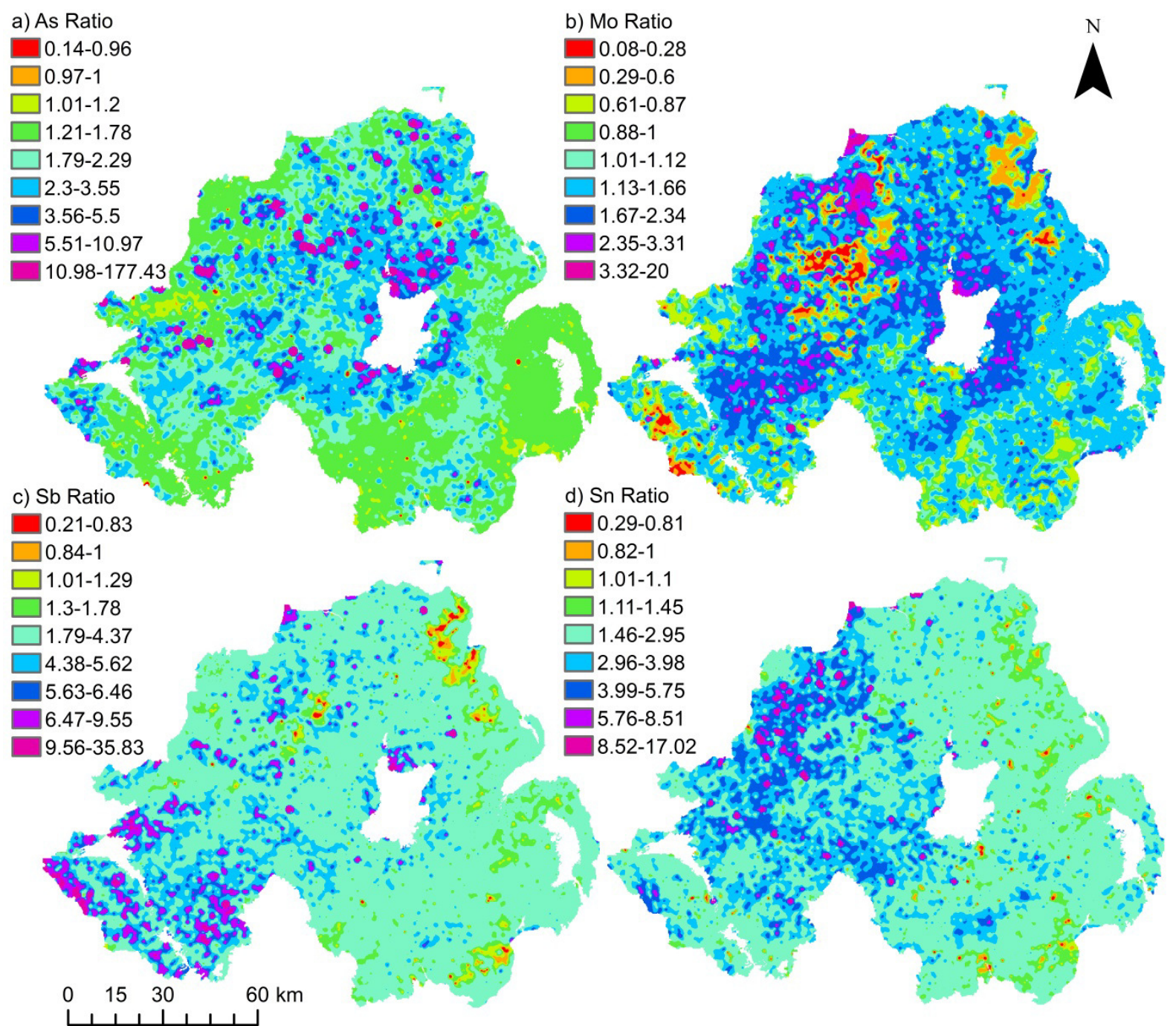

d) Sn Ratio

$\square 0.82-1$

$\square$ 1.01-1.

$\square 1.11-1.45$

2.96-3.98

$3.99-5.75$

$5.76-8.51$

$8.52-17.02$

177 Fig 3 Interpolated ratio (XRF/ICP concentrations) maps for (a) As, (b) Mo, (c) Sb and (d) Sn using shallow soil samples with classes determined using the ECDF method

The red, orange and green areas in Figure $3 \mathrm{~b}$ demonstrate where ICP concentrations are greater than XRF concentrations for Mo. These correlate well with topographically elevated blanket peat, where atmospheric deposition is a possible anthropogenic source of Mo and mineralised domains previously identified for As (Figure 1c). The mineralised domains also contain some of the highest rural concentrations for Mo, suggesting Mo is related to As in these domains and like As, Mo is more easily extracted from these areas. The ICP concentrations of $\mathrm{Sb}$ are also greater than the XRF concentrations in areas of topographically elevated blanket peat and mineralisation (red and orange areas in Figure 3c). However, the areas of mineralisation showing inconsistencies between the methods are smaller than those identified for Mo. Sn (Figure 3d) shows a slightly different pattern to that presented for $\mathrm{Mo}$ and $\mathrm{Sb}$; with a few areas of topographically elevated blanket peat appearing to show ICP concentrations that are greater than XRF concentrations. It is possible that for the blanket peat samples, which have a very high organic carbon content, XRF will see a decrease in the absolute counts detected for all measured elements (Löwemark et al 2011) i.e. the high organic content is inhibiting the ability of XRF to determine accurate concentrations within the sample. However, this would be expected to 
only apparent for Mo, Sb and Sn, suggesting it is affecting these elements in particular. More research is required to determine why this is the case.

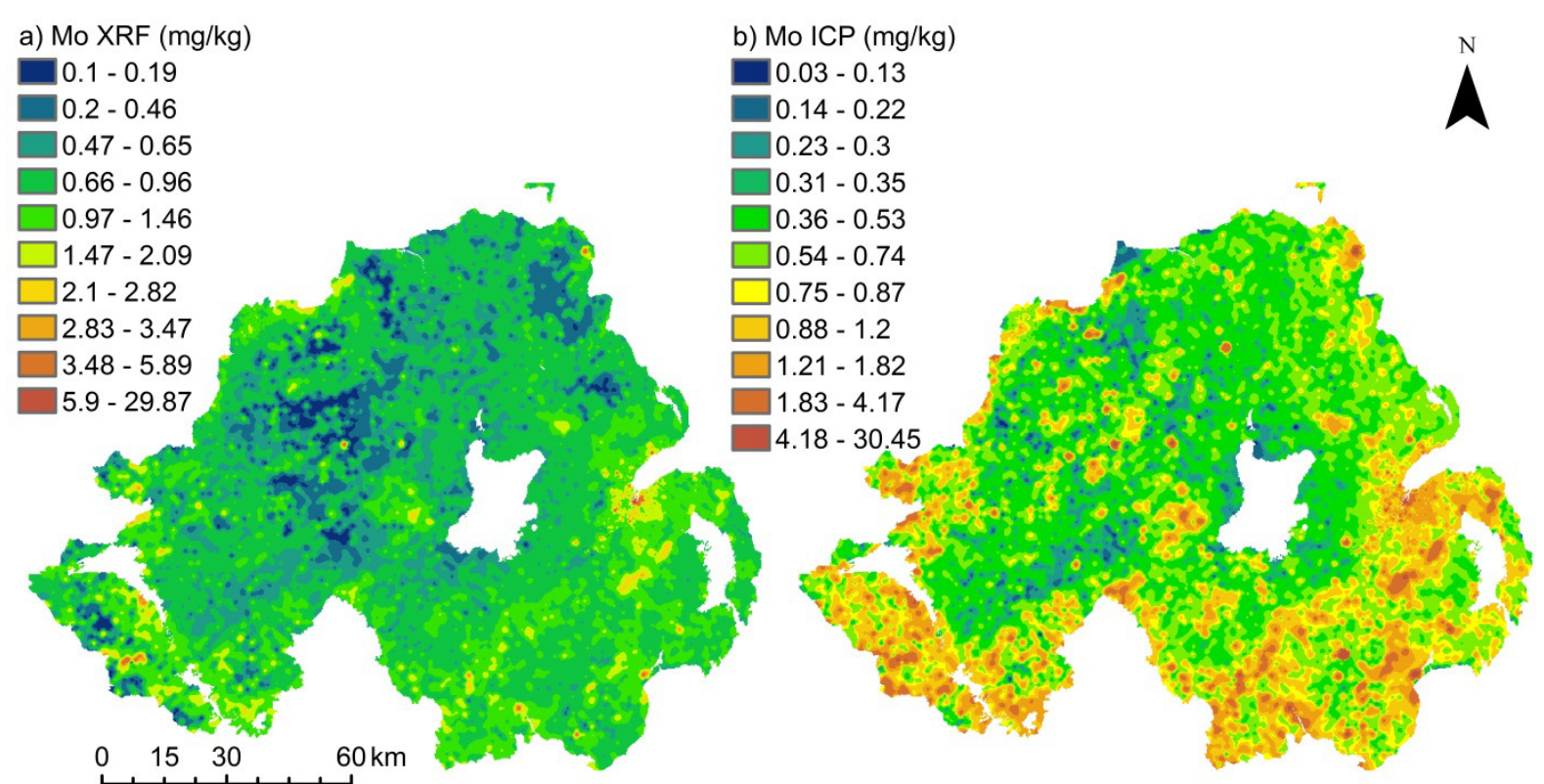

202

203

204

205

206

207

208

209

210

211

212

213

214

215

216

217

218

219

220

221

222
Fig 4 Interpolated concentration maps for Mo as measured by a) XRF and b) ICP following aqua regia digestion with classes determined using the ECDF method

Ultimately, inconsistencies in the two techniques could affect their potential use in environmental studies. A land management method for calculating typical threshold values (TTVs) within identified domains (areas where readily identifiable factors can be shown to control the concentration of an element), uses ECDF classified concentration maps to identify the controlling factors (Mcllwaine et al 2014) over elevated and depleted concentrations. ECDF defined concentration maps for Mo show significant differences depending on the analytical technique used i.e. XRF or ICP following aqua regia digestion (Figure 4). For XRF a depleted domain can be found in areas of blanket peat and an elevated domain in urban areas; in contrast ICP shows elevated domains in both urban areas and areas of mineralisation, creating different domain maps and therefore TTVs. This suggests that care must be taken when considering the use of XRF and ICP following an aqua regia digestion in regional surveys, and attention must be paid to the likely sources and sinks of the elements of interest.

Practical differences between the techniques i.e. the sample size required, how many elements can be analysed and their limits of detection, sample preparation, how destructive the test is and how much it costs, will undoubtedly affect their choice of use for geochemical surveys. In particular, acid digestion prior to analysis via ICP is a time consuming process (Necemer et al 2003; Cobb 2009), whereas the samples for XRF analysis have only to be prepared into pellets. This paper shows that aims of the survey and the likely main controls over element concentrations must be considered alongside these practical differences to ensure that a representative analytical technique is chosen for analysis. 
The two analytical techniques are strongly correlated for elements of geogenic source (Co, $\mathrm{Cr}, \mathrm{Cu}, \mathrm{Ni}$ and $\mathrm{V}$ ) and $\mathrm{Pb}$. For $\mathrm{As}, \mathrm{Mo}, \mathrm{Sb}$ and $\mathrm{Sn}, \mathrm{XRF}$ gives relatively 'dampened' results than ICP for highly organic soil samples that act as sinks for anthropogenic sources and ICP gives 'stronger' results than XRF for mineralised sources. For Mo, Sb and $\mathrm{Sn}$ the ratio between the techniques is less consistent for rural samples than it is for urban samples, possibly because of the source and form of these elements in urban areas. These results show that the techniques are influenced by different factors for certain elements. The chemical form of element present seems to affect ICP, which is appropriate as the solubility of the element in the preceding acid extraction will increase the variability in the final measurement of concentrations by ICP. In contrast analysis by XRF will not include this "solubility" variability, but would be more affected by the sample matrix effects as demonstrated for Mo, Sb and Sn.

This ratio has the potential to estimate element mobility and relative availability based on how easily elements are extracted from different environments. The ratios presented show that elements from anthropogenic sources in urban areas, including those at elevated concentrations, are not always most easily extracted. We show that the most easily extracted forms of some elements are associated with mineralisation domains or with peat domains that act as sinks for anthropogenic contaminants. This suggests that risks posed by these 'anthropogenic' elements are not always associated with urban areas. In addition to total concentrations, extractability data should routinely be considered to screen for potential human and environmental risks.

Following on from these findings, it would be of interest to compare concentrations from other digestion procedures (e.g. the EPA 3051A method discussed above or the 'near-total' digestion composed of nitric, hydrochloric, hydrofluoric and perchloric acids) with concentrations measured by XRF to see how these compare with the aqua regia digestion used in this study. It would also be informative to compare the ratio between the techniques with results from bioavailability testing to determine if the ratio can be used to highlight areas where elements may pose a greater risk in the soil.

\section{Acknowledgements}

253 The Northern Ireland Tellus project was funded by the Northern Ireland Department of 254 Enterprise, Trade and Investment and by the Rural Development Programme through the Northern Ireland Programme for Building Sustainable Prosperity. Rebekka Mcllwaine is funded by the Department of Education and Learning (Northern Ireland). Conflict of Interest: The authors declare that they have no conflict of interest.

\section{$258 \quad 6 . \quad$ Supporting Information}

259 Supporting information available: Table S1 provides a summary of the XRF and ICP 260 analyses completed on the shallow soil samples.

\section{7. References}


Barrat J, Nesbitt R (1996) Geochemistry of the Tertiary volcanism of Northern Ireland. Chem Geol 129:15-38.

Barron AR, Wurzburger N, Bellenger JP, et al (2008) Molybdenum limitation of asymbiotic nitrogen fixation in tropical forest soils. Nat Geosci 2:42-45. doi: 10.1038/ngeo366

Bellenger J-P, Wichard T, Xu Y, Kraepiel AML (2011) Essential metals for nitrogen fixation in a free-living N2-fixing bacterium: chelation, homeostasis and high use efficiency. Environ Microbiol 13:1396-1411.

Bettinelli M, Beone G, Spezia S, Baffi C (2000) Determination of heavy metals in soils and sediments by microwave-assisted digestion and inductively coupled plasma optical emission spectrometry analysis. Anal Chim Acta 424:289-296. doi: 10.1016/S00032670(00)01123-5

Candeias C, Ferreira da Silva E, Salgueiro AR, et al (2011) The use of multivariate statistical analysis of geochemical data for assessing the spatial distribution of soil contamination by potentially toxic elements in the Aljustrel mining area (Iberian Pyrite Belt, Portugal). Environ Earth Sci 62:1461-1479. doi: 10.1007/s12665-010-0631-2

Carrero JA, Arrizabalaga I, Bustamante $\mathrm{J}$, et al (2013) Diagnosing the traffic impact on roadside soils through a multianalytical data analysis of the concentration profiles of traffic-related elements. Sci Total Environ 458-460:427-434. doi: 10.1016/j.scitotenv.2013.04.047

Chander K, Hartmann G, Joergensen RG, et al (2008) Comparison of methods for measuring heavy metals and total phosphorus in soils contaminated by different sources. Arch Agron Soil Sci 54:413-422. doi: 10.1080/03650340801927952

Cobb D (2009) Study on the Effectiveness, Precision, and Reliability of X-ray Fluorescence Spectrometry and Other Alternative Methods for Measuring Lead in Paint.

Cohen DR, Rutherford NF, Morisseau E, Zissimos AM (2012) Geochemical patterns in the soils of Cyprus. Sci Total Environ 420:250-262. doi: 10.1016/j.scitotenv.2012.01.036

Díez M, Simón M, Dorronsoro C, et al (2007) Background arsenic concentrations in Southeastern Spanish soils. Sci Total Environ 378:5-12.

Dzubay TG (ed) (1978) X-Ray Fluorescence Analysis of Environmental Samples, Second Pri. Ann Arbor Science, Michigan

ESRI (Environmental Systems Resource Institute) (2009) ArcMap 10.0.

Fifield F, Haines P (1995) Environmental Analytical Chemistry. Blackie Academic and Professional

Garnham GW, Codd GA, Gadd GM (1993) Uptake of Cobalt and Cesium by Microalgal- and Cyanobacterial-Clay Mixtures. Microbiol Ecol 25:71-82.

Gill R (ed) (1997) Modern Analytical Geochemistry. Addison Wesley Longman

Green KA, Caven S, Lister TR (2010) Tellus Soil Geochemistry - Quality Assessment and Map Production of ICP data. Br. Geol. Surv. Intern. Rep. 
Hill I, Worden R, Meighan I (2001) Formation of interbasaltic laterite horizons in NE Ireland by early Tertiary weathering processes. Geol. Assoc. The Geologists' Association, pp 339-348

Jarva J, Tarvainen T, Lintinen P, Reinikainen J (2009) Chemical Characterization of MetalContaminated Soil in Two Study Areas in Finland. Water Air Soil Pollut 198:373-391. doi: $10.1007 / \mathrm{s} 11270-008-9852-3$

Johnson C, Scheib A, Lister T (2010) London Earth Topsoil Chemical Results : User Guide.

Johnson CC, Ander EL (2008) Urban geochemical mapping studies: how and why we do them. Environ Geochem Health 30:511-530. doi: 10.1007/s10653-008-9189-2

Jordan C, Higgins A (2009) The AFBI Soil Classification Map of Northern Ireland at 1:50,000 scale. Based on information from Cruickshank, J.G. (ed) 1997, Soil and Environment:Northern Ireland. Agricultural and Environmental Science Department, Queen's University, Belfast.

Jordan C, Zhang C, Higgins A (2007) Using GIS and statistics to study influences of geology on probability features of surface soil geochemistry in Northern Ireland. J Geochemical Explor 93:135-152. doi: 10.1016/j.gexplo.2007.03.001

Kisser MI (2005) Digestion of solid matrices Part 1 : Digestion with Aqua Regia. 1-38.

Löwemark L, Chen HF, Yang TN, et al (2011) Normalizing XRF-scanner data: A cautionary note on the interpretation of high-resolution records from organic-rich lakes. J Asian Earth Sci 40:1250-1256. doi: 10.1016/j.jseaes.2010.06.002

Mcllwaine R, Cox SF, Doherty R, et al (2014) Comparison of methods used to calculate typical threshold values for potentially toxic elements in soil. Environ Geochem Health 36:953-971. doi: DOI 10.1007/s10653-014-9611-x

Mitchell W (ed) (2004) The Geology of Northern Ireland, Second Edi. Geological Survey of Northern Ireland, Belfast

Moor C, Lymberopoulou T, Dietrich VJ (2001) Determination of Heavy Metals in Soils, Sediments and Geological Materials by ICP-AES and ICP-MS. Mikrochim A 136:123128.

Necemer M, Kump P, Rajcevic M, et al (2003) Determination of sulfur and chlorine in fodder by X-ray fluorescence spectral analysis and comparison with other analytical methods. Spectrochim Acta Part B 58:1367-1373. doi: 10.1016/S0584-8547

Nieminen TM, Ukonmaanaho L, Shotyk W (2002) Enrichment of $\mathrm{Cu}, \mathrm{Ni}, \mathrm{Zn}, \mathrm{Pb}$ and $\mathrm{As}$ in an ombrotrophic peat bog near a Cu-Ni smelter in southwest Finland. Sci Total Environ 292:81-9.

Niskavaara H, Reimann C, Chekushin V, Kashulina G (1997) Seasonal variability of total and easily leachable element contents in topsoils $(0-5 \mathrm{~cm})$ from eight catchments in the European Arctic (Finland, Norway and Russia). Environ Pollut 96:261-74.

Peltola P, Aström M (2003) Urban geochemistry: a multimedia and multielement survey of a small town in northern Europe. Environ Geochem Health 25:397-419. 
R Core Team (2013) R: A Language and Environment for Statistical Computing.

343

Reimann C, Arnoldussen A, Englmaier P, et al (2007) Element concentrations and variations along a $120-\mathrm{km}$ transect in southern Norway - Anthropogenic vs. geogenic vs. biogenic element sources and cycles. Appl Geochemistry 22:851-871. doi: 10.1016/j.apgeochem.2006.12.019

Reimann C, Filzmoser P, Garrett RG, Dutter R (2008) Statistical Data Analysis Explained: Applied Environmental Statistics with R. John Wiley \& Sons Ltd, Chichester

Reimann C, Garrett RG (2005) Geochemical background--concept and reality. Sci Total Environ 350:12-27. doi: 10.1016/j.scitotenv.2005.01.047

Sahuquillo A, Rigol A, Rauret G (2003) Overview of the use of leaching/extraction tests for risk assessment of trace metals in contaminated soils and sediments. TrAC Trends Anal Chem 22:152-159. doi: 10.1016/S0165-9936(03)00303-0

Salminen R, Tarvainen T (1997) The problem of defining geochemical baselines. A case study of selected elements and geological materials in Finland. J Geochemical Explor 60:91-98. doi: 10.1016/S0375-6742(97)00028-9

Sastre J, Sahuquillo A, Vidal M, Rauret G (2002) Determination of $\mathrm{Cd}, \mathrm{Cu}, \mathrm{Pb}$ and $\mathrm{Zn}$ in environmental samples: microwave-assisted total digestion versus aqua regia and nitric acid extraction. Anal Chim Acta 462:59-72. doi: 10.1016/S0003-2670(02)00307-0

Shotyk W, Cheburkin AK, Appleby PG, et al (1996) Two thousand years of atmospheric arsenic, antimony, and lead deposition recorded in an ombrotrophic peat bog profile, Jura Mountains, Switzerland. Earth Planet Sci Lett 145:E1-E7. doi: 10.1016/S0012821X(96)00197-5

Smyth D (2007) Methods used in the Tellus Geochemical Mapping of Northern Ireland. $\mathrm{Br}$ Geol Surv Open Rep OR/07/022:90pp.

Stolz JF, Oremland RS (1999) Bacterial respiration of arsenic and selenium. FEMS Microbiol Rev 23:615-27.

Thornton I (ed) (1983) Applied Environmental Geochemistry. Academic Press Inc, London

Tighe M, Lockwood P, Wilson S, Lisle L (2004) Comparison of Digestion Methods for ICPOES Analysis of a Wide Range of Analytes in Heavy Metal Contaminated Soil Samples with Specific Reference to Arsenic and Antimony. Commun Soil Sci Plant Anal 35:1369-1385. doi: 10.1081/CSS-120037552

United States Environmental Protection Agency (2007) Microwave assisted acid digestion of sediments, sludges, soils, and oils. Method 3051A Revision 1:1-30.

Wong CSC, Li X, Thornton I (2006) Urban environmental geochemistry of trace metals. Environ Pollut 142:1-16. doi: 10.1016/j.envpol.2005.09.004

Yunker MB, Perreault A, Lowe CJ (2012) Source apportionment of elevated PAH concentrations in sediments near deep marine outfalls in Esquimalt and Victoria, BC, Canada: Is coal from an 1891 shipwreck the source? Org Geochem 46:12-37. doi: 10.1016/j.orggeochem.2012.01.006 
